\title{
EFFECT OF INTRAVENOUS LABETALOL IN CONTROLLING THE CARDIOVASCULAR RESPONSE TO LARYNGOSCOPY AND INTUBATION: A COMPARISON WITH INTRAVENOUS LIGNOCAINE
}

\author{
Raju Prasad Tayung1, Amal Kumar Laha², Tapan Kumar Talukdar³, Jagadish Basumatary4, Ismatara Begum ${ }^{5}$, Bandana Mahanta ${ }^{6}$
}

${ }^{1}$ Registrar, Department of Anaesthesiology, Tezpur Medical College.

${ }^{2}$ Associate Professor, Department of Anaesthesiology, FAA Medical College.

${ }^{3}$ Assistant Professor, Department of Anaesthesiology, Tezpur Medical College.

${ }^{4}$ Associate Professor, Department of Anaesthesiology, Tezpur Medical College.

${ }_{5}^{5}$ Associate Professor, Department of Anaesthesiology, Silchar Medical College.

${ }^{6}$ Associate Professor, Department of Anaesthesiology, Tezpur Medical College.

\begin{abstract}
Laryngoscopy and intubation violates the patient's protective airway reflexes and lead to physiological changes involving various systems of the body. Reflex changes in the cardiovascular system are most marked after laryngoscopy and intubation and leads to average increase in blood pressure by $40-50 \%$ and $20 \%$ increase in heart rate (Indian J. Anaest 2002) 45(2):104-106. The present study compare the safe and clinically effective intravenous bolus dose of labetalol and lignocaine for controlling the cardiovascular response to laryngoscopy and intubation.
\end{abstract}

\section{METHODS}

A total of 90 normotensive adult consented patients aged 20-50 years, ASA grade I and grade II of both gender were randomized into three treatment groups of 30 patients each. Group I received normal saline $10 \mathrm{~mL}$ as infusion. Group II received $1.5 \mathrm{mg} / \mathrm{kg}$ body wt. of lignocaine hydrochloride one minute before intubation. Group III received $0.4 \mathrm{mg} / \mathrm{kg}$ body wt. of labetalol hydrochloride 5 minutes before intubation respectively. Anaesthetic technique was standardized and all groups were assessed for haemodynamic changes after the premedication before and after intubation, at the $1^{\text {st }}, 3^{\text {rd }}, 5^{\text {th }}$ and $10^{\text {th }}$ minute after intubation along with intraoperative haemodynamic stability and post-operative side effects.

\section{RESULTS}

Significant increase in heart rate, systolic blood pressure, diastolic blood pressure and mean arterial pressure were observed in group I after laryngoscopy and intubation. Statistically significant alteration of heart rate, systolic blood pressure and mean arterial pressure but no significant effect in the rise of diastolic blood pressure was observed respectively in group II, whereas statistically highly significant alternation of heart rate, systolic blood pressure, diastolic blood pressure and mean arterial pressure were recorded in Group III.

\section{CONCLUSION}

Intravenous bolus dose of labetalol is superior to lignocaine in attenuating the cardiovascular response to laryngoscopy and intubation. The study patients were haemodynamically stable perioperatively without prolongation of recovery time and side effects.

\section{KEYWORDS}

Labetalol, Lignocaine, Laryngoscopy, Intubation.

HOW TO CITE THIS ARTICLE: Tayung RP, Laha AK, Talukdar TK, et al. Effect of intravenous labetalol in controlling the cardiovascular response to laryngoscopy and intubation: a comparison with intravenous lignocaine. J. Evolution Med. Dent. Sci. 2016;5(63):4405-4410, DOI: 10.14260/jemds/2016/1007

\section{INTRODUCTION}

Laryngoscopy and Endotracheal Intubation are the most important and essential skills in anaesthetic practice. Endotracheal Intubation is an integral part of the anaesthesiologist's contribution to the patient care.

Laryngoscopy and Intubation violates the patient's protective airway reflexes and lead to physiological changes involving various systems of the body. Reflex changes in the cardiovascular system are most marked after laryngoscopy and intubation and leads to average increase in blood pressure by $40-50 \%$ and $20 \%$ increase in heart rate.(1)

Financial or Other, Competing Interest: None.

Submission 14-07-2016, Peer Review 27-07-2016,

Acceptance 29-07-2016, Published 05-08-2016.

Corresponding Author:

Dr. Raju Prasad Tayung,

Department of Anaesthesiology,

Tezpur Medical College,

Dist. - Sonitpur, Assam.

E-mail: drrtayung14@gmail.com

DOI: $10.14260 /$ jemds/2016/1007

The first investigation of the endotracheal intubation on the cardiovascular system was reported in 1940 by Reid and Brace. Numerous reports that followed indicated that cardiovascular disturbances during Laryngoscopy and Intubation do occur. $(2,3)$

The necessity to attenuate these adverse haemodynamic effects has been recognized ever since it was realized that there is cardiovascular instability with Laryngoscopy and Intubation. Topical lignocaine spray,(4,5) Intravenous lignocaine,(6) Deep general anaesthesia, $(3,6)$ Beta adrenoceptor blockers like labetalol,(7) esmolol,(8) central alpha-2 agonist like clonidine,(9) calcium channel blockers like verapamil,(10) nicardipine(11) and vasodilators like sodium nitroprusside ${ }^{(12)}$ have been tried with varying results.

Unfortunately, none of these pharmacological approaches have proved entirely satisfactory, because the reflex may not be completely blocked or the agent used may be too long acting or may have undesirable side effects and additional risks. Till now, no premedication has yet been developed to attenuate the cardiovascular response during laryngoscopy 
and intubation. Different agents to attenuate the cardiovascular response to laryngoscopy and intubation have been tried from time to time.

Intravenous lignocaine has been extensively studied to evaluate its efficacy to attenuate these cardiovascular responses and has been compared with various agents. It has been found to be inconsistently effective.

Labetalol, beta-adrenoceptor blockers has been found to be safe and effective for attenuation of these unwanted cardiovascular responses during laryngoscopy and endotracheal intubation.

In an attempt to observe the haemodynamic changes during laryngoscopy and endotracheal intubation with the use of bolus dose of labetalol and lignocaine, this study has been taken up in Silchar Medical College and Hospital, Silchar, in an endeavour to determine and compare the efficacy of intravenous bolus dose of labetalol to that of lignocaine in controlling the cardiovascular response to laryngoscopy and endotracheal intubation and to determine the side effects profile of these two drugs.

\section{MATERIALS AND METHODS}

The present double-blind randomized placebo controlled study was conducted at Silchar Medical College and Hospital, Silchar, from 1 $1^{\text {st }}$ December 2010 to $30^{\text {th }}$ November 2011 in ninety patients aged between 20 to 50 years of both sexes undergoing elective non-cardiac surgery requiring endotracheal intubation for maintenance of anaesthesia were taken up for study after approval from the Hospital Ethics Committee.

\section{Inclusion Criteria}

1. Patients in the age group of 20-50 years.

2. ASA Grade I and II.

3. Elective surgery under general anaesthesia.

\section{Exclusion Criteria}

1. Physical status other than ASA-I and ASA-II.

2. Any emergency operation.

3. Below 20 years and above 50 years.

4. Baseline Heart Rate $<60 \mathrm{bpm}$ and Baseline Blood Pressure $<100 / 50 \mathrm{mmHg}$.

5. Treatment with $\beta$-adrenergic blocking agents.

6. History of bronchial asthma, cardiac, pulmonary disease and any allergy.

7. Presence of hepatic, renal or any metabolic disorders.

8. Pregnancy.

9. Cases with anticipated difficult intubation.

10. Intubation time $>30$ seconds.

Patients were visited on the pre-operative day and after thorough history and general and systemic examination, pulse rate and blood pressure were recorded. The systolic blood pressure and diastolic blood pressure was recorded by standard NIBP monitor.

For measuring the blood pressure, the same NIBP monitor was used throughout the study. On the night before operation, all patients received Alprazolam $0.25 \mathrm{mg}$ tablet. On the day of operation, blood pressure and pulse rate were recorded. All patients were pre-medicated with: Inj. Glycopyrrolate $0.2 \mathrm{mg}$ I.V. Inj. Diclofenac $75 \mathrm{mg}$ I.M. and Tramadol $1.0 \mathrm{mg} / \mathrm{kg}$ body weight slows I.V. 15 minutes before induction.

Plan of Study
Patients were divided into three groups of thirty (30) patients each. Patients in Group I received pre-intubation doses of $10 \mathrm{~mL}$ normal saline as infusion and were kept as control for comparison of results. Patients in Group II received $1.5 \mathrm{mg} / \mathrm{kg}$ body weight of lignocaine hydrochloride and Group III patients received $0.4 \mathrm{mg} / \mathrm{kg}$ body weight of labetalol hydrochloride respectively. The study drug was administered slowly according to the randomized plan after induction with Thiopentone sodium and vecuronium bromide. The drug lignocaine hydrochloride $(1.5 \mathrm{mg} / \mathrm{kg}$ body weight) was administered intravenously one minute before intubation and labetalol $(0.4 \mathrm{mg} / \mathrm{kg}$ body weight) was administered intravenously as bolus five minutes before intubation respectively.

The patients were pre-oxygenated with $100 \%$ oxygen for three minutes. Induction was done with sleep dose of Thiopentone sodium. Each patient under the study received the appropriate drug according to the group at proper time before laryngoscopy and intubation. Each patient was intubated by using standard intubation dose of vecuronium bromide $(0.08-0.10 \mathrm{mg} / \mathrm{kg}$ body weight) for smooth atraumatic intubation.

Laryngoscopy was done with a Macintosh curved blade laryngoscope and trachea was intubated with Magill's cuffed disposable endotracheal tube within thirty seconds.

Anaesthesia was maintained with oxygen and nitrous oxide in the ratio of 33:67 percent along with isoflurane and vecuronium bromide as top-up doses given when necessary. At the end of the study, positioning and surgery was permitted.

Decurarisation was done at the end of operation with injection neostigmine $0.05 \mathrm{mg} / \mathrm{kg}$ body weight and injection glycopyrrolate $0.01 \mathrm{mg} / \mathrm{kg}$ body weight.

\section{The Parameters that were recorded were \\ - HR \\ - SBP \\ - $\quad$ DBP \\ - MAP}

\section{All Recordings were done}

Before Induction, After Induction, Just before Intubation, Immediately after Intubation, At the $1^{\text {st, }} 3^{\text {rd }}, 5^{\text {th }}, 10^{\text {th }}$ minute after Intubation.

\section{Statistical Analysis}

All the haemodynamic data of the 30 patients from each group were recorded and their average at schedule time interval was calculated. The HR, SBP, DBP and MAP were recorded before induction and these served as the baseline values with which the other readings were compared. The percentage change (Increase or decrease) was calculated and paired test performed to find whether the changes were statistically significant or not.

\section{RESULTS AND OBSERVATIONS}

Ninety patients of ASA Physical Status - I and II of both sexes and aged between 20 and 50 years undergoing various surgical procedures under General Anaesthesia and requiring endotracheal intubation at Silchar Medical College and Hospital, Silchar, during the period of December 2010 to November 2011 were studied to evaluate and compare the efficacy of intravenous bolus dose of labetalol and lignocaine in controlling the cardiovascular responses to laryngoscopy and endotracheal intubation. 


\begin{tabular}{|c|c|c|c|c|c|c|c|c|c|}
\hline \multirow{2}{*}{ Time Interval } & \multicolumn{3}{|c|}{ Group I } & \multicolumn{3}{|c|}{ Group II } & \multicolumn{3}{|c|}{ Group III } \\
\hline & Mean & S.D. & P Value & Mean & S.D. & P Value & Mean & S.D. & P Value \\
\hline Before induction & 79.36 & \pm 5.63 & $>0.05$ & 82.4 & \pm 5.09 & $>0.05$ & 82.76 & \pm 6.12 & $>0.05$ \\
\hline After induction & 80.63 & \pm 5.66 & $<0.05$ & 82.8 & \pm 5.37 & $<0.001$ & 80.36 & 80.36 & $<0.01$ \\
\hline $\begin{array}{l}\text { Just before } \\
\text { intubation }\end{array}$ & 84.23 & \pm 5.23 & $<0.001$ & 79.76 & \pm 11.92 & $<0.001$ & 78.5 & 78.5 & $<0.01$ \\
\hline $\begin{array}{c}\text { Immediately after } \\
\text { intubation }\end{array}$ & 95.43 & \pm 5.95 & $<0.001$ & 90.43 & \pm 3.29 & $<0.001$ & 86.7 & 86.7 & $<0.01$ \\
\hline $\begin{array}{l}\text { At } 1 \text { minute after } \\
\text { intubation }\end{array}$ & 101.33 & \pm 4.20 & & 93.76 & \pm 3.72 & $<0.001$ & 87.33 & 87.33 & $>0.05$ \\
\hline At 3 minutes & 94.66 & \pm 4.85 & & 89.76 & \pm 5.46 & $<0.05$ & 83.73 & 83.73 & $>0.05$ \\
\hline At 5 minutes & 89.23 & \pm 4.08 & & 86.3 & \pm 5.60 & $>0.05$ & 81.1 & 81.1 & $>0.05$ \\
\hline At 10 minutes & 81.13 & \pm 4.20 & & 81.16 & \pm 5.53 & & 81.16 & 81.16 & \pm 4.42 \\
\hline
\end{tabular}

From Table 3, it is seen that the mean baseline heart rate of patients in Group I, Group II and Group III were not found to be statistically different and remained similar $(\mathrm{P}>0.05)$ between the groups after induction also. In Group I, there was significant rise of pulse rate immediately after laryngoscopy and intubation at 1 minute and 3 minutes $(<0.001)$. The pulse rates increased after laryngoscopy and intubation in all the three groups. In Group I and II, changes were highly significant $(\mathrm{P}<0.001)$ after intubation and at 1 minute, 3 minutes and 5 minutes post intubation, after which it was returned towards baseline by 10 th minutes $(\mathrm{P}>0.05)$ in both groups. In Group III, a definitely significant fall in heart rate occurred following injection of labetalol which again increased after laryngoscopy and intubation which is definitely significant $(\mathrm{P}<0.01)$ at immediately after intubation and at 1 minute. The changes returned toward baseline by 3 minutes post intubation $(\mathrm{P}>0.05)$.

\begin{tabular}{|c|c|c|c|c|c|c|c|c|c|}
\hline \multirow{2}{*}{ Time Interval } & \multicolumn{2}{|c|}{ Group I } & \multicolumn{2}{c|}{ Group II } & \multicolumn{3}{c|}{ Group III } \\
\cline { 2 - 10 } & Mean & S.D. & P value & Mean & S.D. & P value & Mean & S.D. & P value \\
\hline Before Induction & 122.1 & \pm 4.99 & $>0.05$ & 122.6 & \pm 4.32 & $>0.05$ & 122.33 & \pm 3.93 & $>0.05$ \\
\hline After Induction & 121.5 & \pm 3.77 & $>0.05$ & 121.73 & \pm 3.67 & $>0.05$ & 120.73 & \pm 3.37 & $<0.001$ \\
\hline $\begin{array}{c}\text { Just } \\
\text { Before Intubation }\end{array}$ & 121.4 & \pm 2.62 & $<0.001$ & 121.8 & \pm 2.89 & $<0.001$ & 117.66 & \pm 3.68 & $<0.05$ \\
\hline $\begin{array}{c}\text { Immediately after } \\
\text { Intubation }\end{array}$ & 156.8 & \pm 6.71 & $<0.001$ & 144.26 & \pm 4.16 & $<0.001$ & 126.53 & \pm 4.34 & $<0.001$ \\
\hline At 1 minute & 164.03 & \pm 3.56 & $<0.001$ & 141.36 & \pm 5.32 & $<0.001$ & 130.23 & \pm 4.82 & $>0.05$ \\
\hline At 3 minutes & 158.56 & \pm 5.87 & $<0.001$ & 132.63 & \pm 5.35 & $>0.05$ & 123.43 & \pm 4.37 & $>0.05$ \\
\hline At 5 minutes & 143.21 & \pm 5.21 & $>0.05$ & 123.66 & \pm 3.76 & $>0.05$ & 122.00 & \pm 3.33 & $>0.05$ \\
\hline At 10 minutes & 123.16 & \pm 3.34 & \multicolumn{9}{|c|}{ Table 2: Systolic Blood Pressure Distribution } & 122.33 & \pm 2.77 & \multicolumn{5}{c|}{} \\
\hline \multicolumn{7}{|c|}{}
\end{tabular}

From Table 2, it is seen that in Group I there was a highly significant $(\mathrm{P}<0.001)$ rise in systolic blood pressure after intubation, which remained so up to the $5^{\text {th }}$ minute in comparison to baseline $(\mathrm{P}<0.001)$ and returned to the baseline at $10^{\text {th }}$ minute post intubation $(\mathrm{P}>0.05)$. In Group II, there was a significant $(\mathrm{P}<0.001)$ rise in systolic blood pressure immediately after intubation, at 1 minute and 3 minutes after which the change was not significant in comparison to baseline ( $\mathrm{P}>0.05)$. In Group III, there was a highly significant fall in systolic blood pressure following injection of labetalol followed by a rise after intubation and at 1 minute after intubation. The blood pressure changes were insignificant at 3,5 and $10^{\text {th }}$ minutes when compared to baseline in Group III ( $\mathrm{P}>0.05)$.

\begin{tabular}{|c|c|c|c|c|c|c|c|c|c|}
\hline \multirow{2}{*}{ Time Interval } & \multicolumn{3}{|c|}{ Group I } & \multicolumn{3}{|c|}{ Group II } & \multicolumn{2}{|c|}{ Group I } & \multirow{2}{*}{$\begin{array}{l}\text { II } \\
\mathbf{p}\end{array}$} \\
\hline & Mean & S.D. & $\mathbf{p}$ & Mean & S.D. & $\mathbf{p}$ & Mean & S.D. & \\
\hline & & & value & & & value & & & value \\
\hline Before Induction & 83.23 & \pm 4.19 & $<0.05$ & 83.83 & \pm 3.33 & $>0.05$ & 83.03 & \pm 4.44 & $<0.05$ \\
\hline After Induction & 79.06 & \pm 3.69 & $<0.001$ & 81.16 & \pm 3.49 & $<0.001$ & 80.11 & \pm 4.45 & $<0.001$ \\
\hline $\begin{array}{l}\text { Just before } \\
\text { Intubation }\end{array}$ & 76.8 & \pm 4.89 & $<0.001$ & 78.23 & \pm 3.51 & $<0.001$ & 76.43 & \pm 4.84 & $<0.001$ \\
\hline $\begin{array}{c}\text { Immediately } \\
\text { After Intubation }\end{array}$ & 90.76 & \pm 4.98 & $<0.001$ & 92.13 & \pm 4.32 & $<0.001$ & 87.4 & \pm 4.36 & $<0.001$ \\
\hline At 1 minute & 95.33 & \pm 4.34 & $<0.001$ & 95.06 & \pm 3.11 & $<0.001$ & 86.73 & \pm 2.86 & $>0.05$ \\
\hline At 3 minutes & 89.99 & \pm 4.17 & $>0.05$ & 89.76 & \pm 4.42 & $>0.05$ & 83.36 & \pm 3.45 & $>0.05$ \\
\hline At 5 minutes & 83.26 & \pm 3.72 & $>0.05$ & 82.86 & \pm 3.94 & $>0.05$ & 81.63 & \pm 3.80 & $>0.05$ \\
\hline At 10 minutes & 81.13 & \pm 3.94 & & 81.43 & \pm 2.83 & & 80.1 & \pm 4.36 & \\
\hline \multicolumn{10}{|c|}{ Table 3: Diastolic Blood Pressure Distribution } \\
\hline
\end{tabular}


From Table 3, it is seen that in Group I there is a highly significantly rise in diastolic blood pressure following intubation $(\mathrm{P}<0.001)$, which remains so up to 1 and 3 minutes post intubation. The changes have become insignificant $(\mathrm{P}>0.05)$ at $5^{\text {th }}$ and $10^{\text {th }}$ minute when compared to baseline. In Group II, there is a highly significant fall in $(\mathrm{P}<0.001)$ DBP following injection of lignocaine, which then increased significantly following intubation $(\mathrm{P}<0.001)$ and remain highly significant at 1 and 3 minutes post intubation. The changes are insignificant both at $5^{\text {th }}$ and $10^{\text {th }}$ minute post intubation. In Group III, there is a highly significant fall in diastolic blood pressure following injection of labetalol followed by a highly significant rise $(\mathrm{P}<0.001)$ immediately after intubation and 1 minute post intubation. The changes are statistically insignificant at $3 \mathrm{rd}$, 5th and 10 th minute when compared to baseline.

\begin{tabular}{|c|c|c|c|c|c|c|c|c|c|}
\hline \multirow{2}{*}{ Time Interval } & \multicolumn{2}{|c|}{ Group I } & \multicolumn{4}{|c|}{ Group II } & \multicolumn{3}{|c|}{ Group III } \\
\hline & Mean & S.D. & p value & Mean & S.D. & P value & Mean & S.D. & P value \\
\hline Before Induction & 94.78 & \pm 4.75 & $>0.05$ & 96.89 & \pm 2.44 & $>0.05$ & 96.33 & \pm 3.69 & $<0.05$ \\
\hline After Induction & 93.40 & \pm 2.93 & $<0.001$ & 94.46 & \pm 3.32 & $<0.001$ & 91.11 & \pm 4.75 & $<0.001$ \\
\hline $\begin{array}{l}\text { Just before } \\
\text { Intubation }\end{array}$ & 89.98 & \pm 3.04 & $<0.001$ & 92.04 & \pm 3.27 & $<0.001$ & 89.98 & \pm 4.55 & $<0.001$ \\
\hline $\begin{array}{l}\text { Immediately after } \\
\text { Intubation }\end{array}$ & 112.41 & \pm 5.82 & $<0.001$ & 109.75 & \pm 3.25 & $<0.001$ & 100.35 & \pm 3.62 & $<0.001$ \\
\hline At 1 minute & 118.20 & \pm 3.31 & $<0.001$ & 110.97 & \pm 4.20 & $<0.001$ & 101.55 & \pm 3.41 & $>0.05$ \\
\hline At 3 minutes & 112.92 & \pm 3.26 & $<0.001$ & 103.70 & \pm 4.09 & $>0.05$ & 96.46 & \pm 2.74 & $>0.05$ \\
\hline At 5 minutes & 102.98 & \pm 2.9 & $>0.05$ & 96.46 & \pm 3.12 & $>0.05$ & 94.99 & \pm 3.11 & $>0.05$ \\
\hline At 10 minutes & 94.33 & \pm 3.15 & & 94.67 & \pm 2.70 & & 94.13 & \pm 3.29 & \\
\hline \multicolumn{10}{|c|}{ Table 4: Mean Arterial Pressure Distribution } \\
\hline
\end{tabular}

From Table 4, it is seen that in Group I there is a highly significant rise of mean arterial pressure $(\mathrm{P}<0.001)$ following intubation which remain so up to $5^{\text {th }}$ minute, the changes are insignificant $(\mathrm{P}>0.05)$ at 10 minutes after intubation when compared to baseline. In Group II, a highly significant rise in mean arterial pressure is observed immediately after intubation at 1 and 3 minutes $(\mathrm{P}<0.001)$ post intubation. The changes are insignificant $(\mathrm{P}>0.05)$, both $5^{\text {th }}$ and $10^{\text {th }}$ minute post intubation. In Group III, a highly significant rise in mean arterial pressure occurs and remain so up to 1 minute $(\mathrm{P}<0.001)$; the changes return to their baseline values by 3 minutes $(\mathrm{P}>0.05)$ post intubation.

\section{DISCUSSION}

Intubation of the trachea alters respiratory and cardiovascular physiology via reflex responses and by the physical presence of the endotracheal tube. The usual circulatory responses to laryngeal and tracheal stimulation in anaesthetized subjects are tachycardia and rise in arterial pressure.

The necessity to attenuate the cardiovascular responses to laryngoscopy and endotracheal intubation at least under certain circumstances is well established. In this study, we have compared the efficacy of a single pre-intubation intravenous bolus dose of labetalol in attenuating these cardiovascular responses to that of a similarly administered dose of lignocaine, which has previously been reported to blunt these responses.

Several regimes have been designed by various authors using different drugs and techniques in an attempt to counter the reflex cardiovascular stimulation to laryngoscopy and intubation. Lignocaine, a local anaesthetic agent had been shown to be used both via topical(4) and intravenous( ${ }^{(6)}$ route are found to be associated with inconsistent result.(13) In our present study, we use lignocaine in the dose of $1.5 \mathrm{mg} / \mathrm{kg}$ body weight which is similar to that of R. Joseph et al, (1996) Labetalol $\beta$-adrenoceptor blockers has been found to be safe and effective in controlling cardiovascular responses to laryngoscopy and intubation without causing significant hypotension. In our study, we have used labetalol $0.4 \mathrm{mg} / \mathrm{kg}$ of the drug as a single intravenous bolus dose five minutes prior to intubation. This dosage is similar to that used by Keun et al(14) who had shown beneficial effect of the drug during intubation. This hypotensive effect is dose related as shown by Lee IO et al.(15) They used bolus dose of labetalol to control the haemodynamic responses to tracheal intubation.

\section{Haemodynamic Variables}

In our study, we recorded the heart rate, systolic and diastolic blood pressure. The mean blood pressure was calculated. Continuous lead II ECG was monitored for any changes in cardiac rhythm. The percentage change (increase or decrease) of haemodynamic variables from the baseline were observed, student 't-test' was performed to find the statistical significance of these changes.

\section{Heart Rate (HR)}

Study of HR variability in Group I (control group) revealed that following induction there was a transient rise in HR $(1.60 \%)$, which is statistically not significant. Again, there was a rise of HR (6.13\%) that observed just before intubation and might be attributed due to sympathetic stimulation following mask ventilation. Following intubation, however, the HR rose dramatically up to $27.68 \%$ at 1 minute followed by a gradual decline. The rise was very highly significant $(\mathrm{P}<0.001)$ as compared to baseline. The values return to baseline at $10^{\text {th }}$ minute post intubation $(\mathrm{P}>0.05)$ (Table 1$)$. Group II also showed a similar observation as compared to Group I. Here also marked rise to HR occurred and peaked at 1 minute; (13.78\%) post intubation which was statistically highly significant $(\mathrm{P}<0.001)$. The rise persisted to be significant $(\mathrm{P}<0.05)$ up to 5 minutes post intubation and then became insignificant at 10 minutes $(\mathrm{P}>0.05)$ post-intubation (Table 1).

Moving on to Group III, the baseline pulse rate was 82.76 \pm 6.12 . Following injection of labetalol, a significant fall of HR $(-5.14 \%)$ was recorded just before intubation of trachea $(\mathrm{P}<0.01)$. At interval of 1 minute following intubation, the pulse rate was only $87.33 \pm 4.45$ (a rise of $5.52 \%$ ), which is found to be significant as compared to baseline $(\mathrm{P}<0.01)$. The 
rate was kept constant around the baseline value at 3 minutes post-intubation $(\mathrm{P}>0.05)$ (Table 1$)$.

During intergroup comparison, the HR of Group I and Group-II showed highest increased at 1 minute post intubation $(27.68 \%$ vs. $13.78 \%$, respectively). The other variables at different intervals were also comparable among the two groups (Table 1). The difference is found to be statistically highly significant $(\mathrm{P}<0.001)$ up to 3 minutes postintubation and just significant $(\mathrm{P}<0.05)$ at 5 minutes postintubation and returned to baseline at 10 minutes postintubation (Table 1).

Contrary to control and lignocaine group, labetalol group showed a highly significant fall in HR $(-5.14 \%)$ that was observed before laryngoscopy and intubation (Table 5.3). At 1 minute post intubation, the rise was only $5.52 \%$ as compared to $27.68 \%$ in Group I and $13.78 \%$ and Group II respectively. These findings in Group III, when compared to Group I and II were found to be highly significant $(\mathrm{P}<0.001)$ (Table1).

Eiichi et al(16) also found that labetalol intravenous just prior to induction of anaesthesia is a safe and cost effective means of preventing tachycardia in response to laryngoscopy and intubation. In our study also, labetalol $0.4 \mathrm{mg} / \mathrm{kg}$ intravenous injection almost prevented the rise of HR following laryngoscopy and intubation as compared to control group and lignocaine group.

\section{Systolic Blood Pressure (SBP)}

In Group I, the baseline blood pressure was $122.1 \pm 4.99$ mmHg. There was a transient fall after intubation (A fall of $0.57 \%$ ). This may be attributed to the vasodilator effect of thiopentone and has no significance statistically. A marked rise of SBP was noted immediately after intubation and at 1 minute post-intubation and remained statistically significant $(\mathrm{P}<0.001)$ up to 5 minutes and settled towards baseline value by 10 minutes (Table 2 ).

In Group II, the baseline systolic blood pressure was $122.6 \pm 4.32 \mathrm{mmHg}$. After intubation, the pressure rose only $17.66 \%$ above pre-induction value immediately after intubation, which is still significant $(\mathrm{P}<0.001)$ when compared to baseline value. The pressure returned to baseline earlier than Group I at 5 minutes post intubation (Table 2).

In Group III, the initial SBP was $122.33 \pm 3.98 \mathrm{mmHg}$, which rose to $130.23 \pm 4.82 \mathrm{mmHg}(6.45 \%)$ at 1 minute post intubation and was statistically significant $(\mathrm{P}<0.001)$. The values settled to baseline at 3 minutes post intubation (Table 2).

On comparing Group I and Group II, we see a highly significant rise in blood pressure in Group I which remained above baseline $(\mathrm{P}<0.001)$ till 5 minutes post intubation. The difference is also found to be highly significant $(\mathrm{P}<0.001)$ immediately after intubation and at 1,3 and 5 minute postintubation (Table 2). No significant difference was observed statistically at 10 minutes post-intubation ( $\mathrm{P}>0.05)$.

Again in Group I and Group III, we observed a highly significant fall $(\mathrm{P}<0.001)$ in systolic blood pressure after injection of labetalol in the Group III $(-3.81 \%)$. Both the groups showed an increase in SBP following intubation, but the percentage change was very much higher in Group I than Group III (34.34\% vs. $6.45 \%$ respectively) at 1 minute postintubation. The values returned towards baseline after 3 minutes in Group III, persisted to be high in Group I up to 5 minutes (17.28\%) vs. $0.26 \%$ in Group I and Group III respectively). The difference was statistically insignificant $(\mathrm{P}>0.05)$ at $10^{\text {th }}$ minute post-intubation.

Regarding Group II and Group III, the rise of SBP following intubation at 1 and 3 minutes post-intubation was found to be highly significant $(\mathrm{P}<0.001)$. In both the groups, the values returned to their baseline at 5 minutes postintubation. There was significant difference $(\mathrm{P}<0.05)$ when compared among these two groups.

From these observations regarding systolic blood pressure and heart rate, we can infer that labetalol causes fall in both heart rate and SBP than lignocaine, which has little effect on heart rate.

The reflex rise in SBP and heart rate could be attenuated well with the use of labetalol. In our study in Group II the changes in pulse rates are similar to Group I (Control group), but there was significant attenuation of SBP following intubation and it is statistically highly significant $(\mathrm{P}<0.001)$ when compared to Group I.

Again in Group III, our findings of marked attenuation of heart rate and blood pressure with IV labetalol is highly significant $(\mathrm{P}<0.001)$ when compared to control group. These observations are similar to that of Ramkrishna $\mathrm{V}$ and coworkers.(17)

Bemstein JS and Colleagues(13) concluded from their studies that patients in the 0.25 and $0.75 \mathrm{mg} / \mathrm{kg}$ labetalol groups compared to those in the placebo group had significantly lower increases in peak HR $(33 \pm 2$ and $27 \pm 3$ vs. $44 \pm 7$ beats/minute), peak MAP (38 \pm 6 and $38 \pm 5$ vs. $38 \pm 7$ $\mathrm{mmHg}$ ) and peak rate pressure product $(7,726 \pm 260$ and $7,215 \pm 300$ vs. $14,023 \pm 250$ units). The results show that these doses of labetalol significantly blunt, but do not completely block, autonomic responses to rapid sequence induction and intubation - which is similar to our observation.

\section{Diastolic Blood Pressure (DBP)}

In Group I (control) the mean baseline DBP was $83.23 \pm 6.66$ $\mathrm{mmHg}$, which rise dramatically $(\mathrm{P}<0.001)$ to $95.33 \pm 4.34$ mmHg after 1 minute post-intubation. Thereafter, it fell gradually and remained above baseline at 10 minutes postintubation (Table 3).

In Group II and III, the baseline DBP was $83.83 \pm 3.33$ $\mathrm{mmHg}$ and $80.03 \pm 4.44 \mathrm{mmHg}$ respectively. After intubation, the pressure increased to $95.06 \pm 3.11$ and $86.73 \pm 2.86$ in Group II and III respectively at 1 minute post-intubation. When compared to baselines, these values were highly significant $(\mathrm{P}<0.001)$ in both the groups. Again the magnitude of percentage rise was less in both the groups in comparison to Group I and it is highly significant $(\mathrm{P}<0.001)$ statistically immediately after intubation and at 1 and 3 minutes postintubation (Table 3).

Again when we see Group II and III, we observe that both lignocaine and labetalol could not effectively block the rise of diastolic blood pressure following intubation (9.04 and $5.26 \%$ ) in Group III and II respectively) at 1 minute interval (Table 3). However, the pressure returned towards baseline at a faster rate in both the groups and there was high statistical significance between these two groups up to 3 minutes post-intubation $(\mathrm{P}<0.001)$ (Table 3$)$.

\section{Mean Arterial Pressure (MAP)}

The baseline MAP in the control group was $94.78 \pm 4.75$ $\mathrm{mmHg}$. This value increased to $118.20 \pm 3.31 \mathrm{mmHg}$ at 1 minute post-intubation and subsequently touched baseline at 
10 minutes $(94.33 \pm 3.15 \mathrm{mmHg}$ ). In Group II and III also, MAP increased from their baseline values $96.89 \pm 2.44$ and $96.33 \pm 3.69$ to $110.97 \pm 4.20$ and $101.55 \pm 3.41 \mathrm{mmHg}$ respectively. This is highly significant $(\mathrm{P}<0.001)$ compared to their baseline values. In both the groups, the pressure settled at 5 minutes and remained stable throughout the study.

On comparing Group I and Group II, we see that rise of MAP occurred in both groups. Although the magnitude of percentage rise was less in Group II (24.70\% versus 14.53\%), difference is still statistically highly significant $(\mathrm{P}<0.001)$ up to 5 minutes post-intubation (Table 13.1). In Group I and III, the rise was $24.70 \%$ and $5.41 \%$ respectively at 1 minute postintubation, which is also found to be statistically highly significant $(\mathrm{P}<0.001)$ when compared between these two variables.

Again comparison between Group II and Group III reveals that values in both the groups at each time interval were comparable. The pressure settled towards baseline at 5 minutes post-intubation in both the groups $(\mathrm{P}>0.05)$ (Table 4) and statistically high difference was observed when compared among these two groups $(\mathrm{P}<0.001)$ following laryngoscopy and intubation.

Lee IO and Colleagues (1995) observed that dose of labetalol $1.5 \mathrm{mg} / \mathrm{kg}$ produced significant ablation of SBP (146.6 $\pm 8.6 \mathrm{mmHg}$ compared to $165.5 \pm 17.6 \mathrm{mmHg}$, 162.0 $\pm 19.7 \mathrm{mmHg}$ and 158.4 $\pm 17.6 \mathrm{mmHg}$ in Group 1, 2 and 3 respectively) after tracheal intubation.

All labetalol groups produced less changes in HR ( $97.3 \pm 7.5$ beats per minute, $97.5 \pm 12.7$ beats per minute, $97.5 \pm 11.8$ beats per minute and $107.7 \pm 14.0$ beats per minute in Group 2, 3, 4 and 1 respectively) after tracheal intubation, but were not significantly different in all groups. They suggested that the pressure responses to tracheal intubation were significantly controlled by labetalol $1.5 \mathrm{mg} / \mathrm{kg}$ bolus injection prior to induction and simultaneously they have given attention to the side effects until postoperative period. They also suggested that labetalol bolus injection prior to induction blunted HR changes caused by tracheal intubation.

So it is concluded that with labetalol the control of reflex rise of haemodynamic parameters during intubation, the control of HR, SBP, DBP and MAP are much better achieved than with lignocaine.

\section{CONCLUSION}

To conclude, we have observed in our study that intravenous bolus dose of labetalol is superior to lignocaine in attenuating the cardiovascular responses to laryngoscopy and endotracheal intubation by virtue of its reduction in HR, SBP, DBP and MAP respectively.

Lignocaine, on the other hand can attenuate the rise in HR, SBP and MAP, but has no significant effect in the rise of DBP respectively.

Considering all the above factors, we may conclude that labetalol can be taken as superior and acceptable to lignocaine in the attenuation of haemodynamic responses during laryngoscopy and endotracheal intubation.

However, a larger trial with more number of patients will give us a definite conclusion.

\section{REFERENCES}

1. Ghaus M, Singh V, Kumar A, et al. A Study of cardiovascular response during laryngoscopy and intubation and their attenuation by ultrashort acting $\mathrm{b}$ blocker esmolol. Indian J Anaest 2002;46(2):104-106.
2. Burstein CL, LoPinto FJ, Newman W. Electrocardiographic studies during endotracheal intubation. I. Effects during usual routine technics. Anaesthesiology 1950;11(2):224-37.

3. King BD, Harris LC, Griefenstein FE, et al. Reflex circulatory responses to direct laryngoscopy and tracheal intubation performed during general anaesthesia. Anaesthesiology 1951;12(5):556-66.

4. Wycoff CC. Endotracheal intubation: effects on blood pressure and pulse rate. Anaesthesiology 1960;21(2):153-8.

5. Delinger JK, Ellison N, Ominsky AJ. Effects of intratracheal lidocaine on circulatory responses to tracheal intubation. Anaesthesiology 1974;41(4):409-12.

6. Abou-Madi MN, Keszler H, Yacoub JM. Cardiovascular reactions to laryngoscopy and endotracheal intubation following small and large intravenous doses of lidocaine. Canad Anaesth Soc J 1997;24(1):12-9.

7. Leslie JB, Kalayjian RW, McLoughlin TM, et al. Attenuation of the hemodynamic responses to endotracheal intubation with pre-induction intravenous labetalol. Journal of Clinical Anesthesia 1989;1(3):194200.

8. Shree SR, Badrinarayan V. Evaluation of three regimens of esmolol for attenuation of cardiovascular response to endotracheal intubation-a comparison with intravenous lignocaine. J Anaest Clin Pharmacol 2003;19(1):45-52.

9. Batra YK, Indu B, Puri GD. Attenuation of pulse rate and blood pressure response to laryngoscopy and tracheal intubation by clonidine. Int J Clin Pharmacol Ther Toxicol 1988;26(7):360-3.

10. Goverdhan PD, Batra YK. Effect of nifedipine on the cardiovascular response to laryngoscopy and intubation. Brit J Anaesh 1988;60(5):579-81.

11. Charuluxananan S, Kyokong O, Somboonviboon W, et al. Nicardipine versus lidocaine for attenuating the cardiovascular response to endotracheal intubation. Journal of Anaesthesia 2000;14(2):77-81.

12. Stoelting RK. Attenuation of blood pressure responses to laryngoscopy and tracheal intubation with sodium nitroprusside. Anaesth Analg 1979;58(2):116-9.

13. Bernstein JS, Ebert TJ, Stowe DF, et al. Partial attenuation of hemodynamic responses to rapid sequence induction \& intubation with labetalol. J ClinAnesth 1989;1(6):44451.

14. Chung KS, Sinatra RS, Chung JH. The effect of an intermediate dose of labetalol on heart rate and blood pressure responses to laryngoscopy and intubation. Journal of Clinical Anaest 1992;4(1):11-5.

15. Lee IO. Effect of pre-induction intravenous labetalol on cardiovascular responses to tracheal intubation. Korean J Anesthesiol 1995;29(1):42-49.

16. Inada E, Cullen DJ, Nemeskal AR, et al. Effect of labetalol or lidocaine on the hemodynamic response to intubation: a controlled randomized double-blind study. Journal of Clinical Anesthesia 1989;1(3):207-13.

17. RamaKrishna V, Wig J, Singh H, et al. Can labetalol be used to attenuate the cardiovascular responses to laryngoscopy and endotracheal intubation? Journal of Anaesthesiology Clinical Pharmacology 1988;4(4): 227-32. 